J. Math. and Its Appl.

E-ISSN: 2579-8936

P-ISSN: 1829-605X

Vol. 14, No. 2, Desember 2017, 127-143

\title{
Analisa Penentuan Sisa Umur Bearing Menggunakan Fungsi Mean Residual Life (Studi Kasus Pada Mesin Sakurai Oliver-66 CV. Bintang Cakra)
}

\author{
Bella Dinda Famela ${ }^{1}$, Valeriana Lukitosari ${ }^{2}$,Wahyu Fistia Doctorina ${ }^{3}$ \\ Departemen Matematika, Fakultas MIPA, Institut Teknologi Sepuluh Nopember (ITS) \\ Jl. Arief Rahman Hakim, Surabaya 60111 Indonesia \\ belladinda16@gmail.com ${ }^{1}$,valerianaluki@gmail.com ${ }^{2}$, \\ wahyu_fistia@matematika.its.ac.id ${ }^{3}$
}

\begin{abstract}
Abstrak
Kerusakan pada bearing sering terjadi dalam dunia industri cetak offset, padahal bearing mempunyai peran penting sebagai pendukung pada putaran poros. Jika bearing tidak berfungsi dengan baik maka prestasi seluruh sistem tidak dapat bekerja secara semestinya. Dengan adanya gangguan tersebut tentunya akan menimbulkan kerugian pada pihak perusahaan tersebut akibat hilangnya waktu produksi selama proses berlangsung. Tujuan dari penelitian ini adalah untuk mengetahui keandalan, laju kerusakan, umur, sisa umur bearing dengan metode Least Square dan metode Estimasi Maksimum Likelihood (MLE). Simulasi dengan 4 bearing yang terpilih berdasarkan Maksimum Likelihood (MLE). Simulasi dengan 4 bearing yang terpilih berdasarkan owntime terbesar. Sehingga didapatkan nilai taksiran sisa umur metode Least Square bearing $6001 \mathrm{ZZ} 11$ hari 18 jam; bearing 6205 ZZ 16 hari 21 jam; bearing 0606 ZZ 9 hari 15 jam, thrust bearing 7 hari 13 jam. Sedangkan metode Estimasi Maksimum Likelihood dari bearing $6001 \mathrm{ZZ} 23$ hari 10 jam; bearing 6205 ZZ 25 hari 1 jam; bearing 0606 ZZ 29 hari 1 jam, thrust bearing 19 hari 14 jam.

Kata Kunci-keandalan, laju kerusakan, sisa umur, umur.
\end{abstract}

\section{Pendahuluan}

Industri dapat dijadikan sebagai indikator terjadinya perkembangan ilmu pengetahuan dan teknologi. Dengan berkembangnya ilmu pengetahuan dan teknologi, maka pertumbuhan industri juga akan semakin pesat. Seiring 
dengan majunya industrialisasi dan ketatnya kompetisi, sebuah perusahaan dituntut mampu tetap bertahan dan memenangkan persaingan dengan perusahaan lain. Persoalan yang sering dihadapi dalam dunia industri adalah adanya suatu pernyataan bahwa suatu sistem yang telah dirancang dan dibuat secanggih dan sekompleks apapun pasti akan mengalami gangguan, baik gangguan ringan, sedang maupun berat [1]. Dengan adanya gangguan ini .tentunya akan menimbulkan kerugian pada pihak perusahaan tersebut akibat hilangnya waktu produksi yang dilakukan selama proses berlangsung.

Suatu produk yang baik tentunya harus memperhatikan karakteristik mutunya. Hal-hal yang berhubungan dengan mutu dapat berupa umur atau reliabilitas. Makin lama kemampuan hidup dari produk, dapat dikatakan bahwa mutunya semakin bagus. Peluang suatu produk untuk dapat hidup lebih dari waktu yang telah ditentukan disebut reliabilitas [2]. Setiap produk diharapkan mempunyai reliabilitas yang tinggi, agar produk tersebut disukai oleh konsumen. Untuk menggambarkan intensitas peluang bahwa umur produk akan gagal pada waktu tertentu, merupakan tingkat resiko kegagalan pada waktu tersebut atau yang biasanya disebut dengan laju kerusakan. Nilai ini merupakan rambu-rambu untuk mengetahui tingkat bahaya bahwa bearing akan mengalami kerusakan.

Umur produk merupakan lamanya produk tersebut mampu berfungsi sampai tiba waktu kegagalannya. Sedangkan sisa umur produk merupakan lamanya produk masih berfungsi setelah waktu tertentu. Reliabilitas, umur dan sisa umur produk adalah saling berhubungan. Sehingga dapat dikatakan bahwa mereka merupakan ukuran reliabilitas produk [3]. Ukuran-ukuran ini menyatakan kemampuan berfungsinya produk dari awal hingga muncul kegagalannya.

Salah satu elemen penting pada mesin cetak adalah bearing yang berperan sebagai pendukung pada putaran poros. Bearing merupakan sebuah elemen mesin yang berfungsi untuk membatasi gerak relatif antara dua atau lebih komponen mesin agar selalu bergerak pada arah yang diinginkan. Bearing harus cukup kokoh untuk memungkinkan poros serta 
elemen mesin lainnya bekerja dengan baik. Jika bearing tidak berfungsi dengan baik maka prestasi seluruh sistem tidak dapat bekerja secara semestinya. Kegagalan pada perputaran bearing merupakan salah satu penyebab utama kerusakan dalam sebuah mesin. Kerusakan bearing harus diprediksi dengan akurat karena akan menentuk berapa lama sisa umur fungsi dari sebuah mesin [2]. Oleh karena itu, pemantauan secara dini terhadap kondisi bearing menjadi hal yang penting, sehingga bearing dapat diganti sebelum mengalami kerusakan secara menyeluruh.

Atas dasar itulah maka, dalam penelitian ini akan dilakukan penelitian untuk mengetahui reliabilitas, laju kerusakan, umur dan sisa umur bearing menggunakan metode Estimasi Maksimum Likelihood (MLE) dan metode Least Square. Dalam penelitian ini penulis menggunakan nilai Mean Square Error (MSE) untuk menentukan metode terbaik dalam pendugaan parameter distribusi.

\section{Metode Penelitian.}

\subsection{Studi Literatur}

Tahapan awal yang dilakukan adalah identifikasi masalah dengan pengumpulan teori pendukung mengenai pengertian bearing, keandalan, laju kerusakan, penetuan umur dan penentuan sisa umur pada komponen mesin.

\subsection{Pengumpulan Data}

Pada tahap ini yaitu mengumpulkan data downtime masing-masing bearing pada mesin Sakurai Oliver-66. Disini penulis akan melakukan analisa data sekunder yang telah diolah oleh teknisi mesin untuk menentukan nilai downtime yang terbesar. Bearing dengan nilai downtime terbesar diindikasikan mempunyai jumlah kerusakan yang besar pula, sehingga diperlukan analisa lebih lanjut. Data waktu kerusakan yang akan diolah oleh penulis adalah time to failure (TTF) dimana TTF adalah selang waktu kerusakan awal yang telah diperbaiki hingga terjadi kerusakan berikutnya. 


\subsection{Penentuan Distribusi yang Sesuai}

Pada tahap pengolahan data, hal pertama yang dilakukan adalah menentukan distribusi kerusakan yang paling sesuai dari ke empat distribusi yaitu Eksponensial, Weibull, Lognormal dan Normal pada masing-masing bearing. Untuk menentukan distribusi yang sesuai adalah dengan mencari nilai Index of Fit yang terbesar dari setiap distribusi. Setelah itu dilakukan uji kecocokan distribusi atau Goodness of Fit yang terdiri dari tiga jenis yaitu uji Bartlett untuk distribusi Eksponensial, uji Mann untuk distribusi Weibull dan uji Kolmogorov-Smirnov untuk distribusi Normal dan Lognormal.

\subsection{Penentuan Nilai Parameter}

Pada tahap ini akan dilakukan penentuan nilai parameter dari distribusi yang telah sesuai dengan data downtime dengan metode kuadrat terkecil (least square) dan MLE. Selanjutnya nilai parameter tersebut disubtitusikan kedalam rumus keandalan, laju kerusakan, umur dan sisa umur sehingga diperoleh nilai keandalan, laju kerusakan, umur dan sisa umur dari masingmasing bearing pada mesin cetak Sakurai Oliver-66.

\subsection{Penarikan Kesimpulan}

Dalam tahap akhir penelitian ini dilakukan penarikan kesimpulan dari hasil analisa nilai keandalan, laju kerusakan berdasarkan distribusi yang terpilih dan memperoleh hasil umur dari bearing serta sisa umur bearing.

\section{Analisa dan Pembahasan}

3.1 Reliabilitas, Laju Kerusakan, Umur dan Sisa Umur Distribusi Weibull.

Reliabilitas adalah peluang suatu produk untuk dapat hidup lebih dari waktu yang telah ditentukan [4].

$$
R(t)=e^{-\left(\frac{t}{\theta}\right)^{\beta}}
$$


Untuk menggambarkan intensitas peluang bahwa umur produk akan gagal pada waktu tertentu, merupakan tingkat resiko kegagalan pada waktu tersebut atau yang biasanya disebut dengan laju kerusakan [4].

$$
h(t)=\frac{\beta}{\theta}\left(\frac{t}{\theta}\right)^{\beta-1}
$$

Umur produk merupakan lamanya produk tersebut mampu berfungsi sampai tiba waktu kegagalannya [5].

$$
E(t)=\theta \mathbb{\Gamma}\left(\frac{1}{\beta}+1\right)
$$

Sedangkan sisa umur produk merupakan lamanya produk masih berfungsi setelah waktu tertentu [6].

$$
m(t)=\frac{\int_{t}^{\infty} t f(t) d t}{R(t)}-t
$$

\subsection{Penentuan Distribusi yang Sesuai}

Untuk menentukan distribusi yang sesuai adalah dengan mencari nilai Index of Fit yang terbesar dari setiap distribusi. Setelah itu dilakukan uji kecocokan distribusi atau Goodness of Fit yang terdiri dari tiga jenis yaitu uji Bartlett untuk distribusi Eksponensial, uji Mann untuk distribusi Weibull dan uji Kolmogorov-Smirnov untuk distribusi Normal dan Lognormal. Berikut merupakan hasil perhitungan index of Fit pada masing-masing komponen :

Tabel 1 Hasil Perhitungan index of Fit

\begin{tabular}{|l|l|l|}
\hline Bearing & $\begin{array}{l}\text { Distribusi } \\
\text { Terpilih }\end{array}$ & $\begin{array}{l}\text { Index Of } \\
\text { Fit }\end{array}$ \\
\hline $\begin{array}{l}6001 \\
\mathrm{ZZ}\end{array}$ & Weibull & 0,98891 \\
\hline $\begin{array}{l}6205 \\
\mathrm{ZZ}\end{array}$ & Weibull & 0,98944 \\
\hline $\begin{array}{l}0606 \\
\mathrm{ZZ}\end{array}$ & Weibull & 0,98886 \\
\hline $\begin{array}{l}\text { Thrust } \\
\text { Bearin: }\end{array}$ & Weibull & 0,99065 \\
\hline
\end{tabular}


Setelah diketahui bahwa komponen telah berdistribsi Weibull, maka langkah selanjutnya dilakukan pada tahap uji kesesuaian distribusi dengan menggunakan Uji Mann :

Hipotesa untuk uji ini adalah [7]:

$$
\begin{aligned}
& H_{0}: T=F(t) \\
& H_{1}: T \neq F(t)
\end{aligned}
$$

Sedangkan,

$$
\begin{gathered}
M=\frac{k_{1} \sum_{i=k_{1}+1}^{n-1}\left[\frac{\left(\ln t_{i+1}-\ln t_{i}\right)}{M_{i}}\right]}{k_{2} \sum_{i=1}^{k_{1}}\left[\frac{\left(\ln t_{i+1}-\ln t_{i}\right)}{M_{i}}\right]} \\
M_{i}=Z_{i+1}-Z_{i} \\
Z_{i}=\ln \left[-\ln \left(1-\frac{i-0,3}{n+0,4}\right)\right] \\
k_{1}=\left\lfloor\frac{n}{2}\right] ; k_{2}=\left\lfloor\frac{n-1}{2}\right] \\
v_{1}=2 k_{1} ; v_{2}=2 k_{2} ; F_{\text {tabel }}=F_{\alpha, v_{1}, v_{2}}
\end{gathered}
$$

Jika $M<F_{\text {tabel }}$ maka $H_{0}$ diterima dan $H_{1}$ ditolak.

a. Bearing $6001 \mathrm{ZZ}$

Hipotesa Uji:

$$
\begin{aligned}
& H_{0}: T=F(t) \\
& H_{1}: T \neq F(t):
\end{aligned}
$$

Dengan $\mathrm{n}=8, k_{1}=4 ; k_{2}=3,5 ; v_{1}=8 ; v_{2}=7$ maka didapat nilai $M$ adalah sebagai berikut :

$$
M=\frac{(4)(0,12640)}{(3,5)(0,12043)}=1,19946
$$

Kriteria Uji:

$$
F_{\text {tabel }}=F_{\alpha, v_{1}, v_{2}}=F_{0,05 ; 8 ; 7}=3,73
$$

Didapat nilai $M<F_{\text {tabel }}=1,19946<3,73$ yang artinya $H_{0}$ diterima. Maka dapat disimpulkan data kerusakan terdistribusi Weibull. 
b. Bearing $6205 \mathrm{ZZ}$

Hipotesa Uji:

$$
\begin{aligned}
& H_{0}: T=F(t) \\
& H_{1}: T \neq F(t)
\end{aligned}
$$

Dengan $\mathrm{n}=8, k_{1}=4 ; k_{2}=3,5 ; v_{1}=8 ; v_{2}=7$ maka didapat nilai $M$ adalah sebagai berikut :

$$
M=\frac{(4)(0,12445)}{(3,5)(0,12323)}=1,15421
$$

Kriteria Uji:

$$
F_{\text {tabel }}=F_{\alpha, v_{1}, v_{2}}=F_{0,05 ; 8 ; 7}=3,73
$$

Didapat nilai $M<F_{\text {tabel }}=1,15421<3,73$ yang artinya $H_{0}$ diterima. Maka dapat disimpulkan data kerusakan terdistribusi Weibull.

c. Bearing $0606 \mathrm{ZZ}$

Hipotesa Uji:

$$
\begin{aligned}
& H_{0}: T=F(t) \\
& H_{1}: T \neq F(t
\end{aligned}
$$

Dengan $\mathrm{n}=8, k_{1}=4 ; k_{2}=3,5 ; v_{1}=8 ; v_{2}=7$ maka didapat nilai $M$ adalah sebagai berikut :

$$
M=\frac{(4)(0,12627)}{(3,5)(0,12111)}=1,19154
$$

Kriteria Uji:

$$
F_{\text {tabel }}=F_{\alpha, v_{1}, v_{2}}=F_{0,05 ; 8 ; 7}=3,73
$$

Didapat nilai $M<F_{\text {tabel }}=1,19154<3,73$ yang artinya $H_{0}$ diterima. Maka dapat disimpulkan data kerusakan terdistribusi Weibull.

\section{d. Thrust Bearing}

Hipotesa Uji:

$$
\begin{aligned}
& H_{0}: T=F(t) \\
& H_{1}: T \neq F(t)
\end{aligned}
$$


Dengan $\mathrm{n}=8, k_{1}=4 ; k_{2}=3,5 ; v_{1}=8 ; v_{2}=7$ maka didapat nilai $M$ adalah sebagai berikut :

$$
M=\frac{(4)(0,12875)}{(3,5)(0,11931)}=1,12332
$$

Kriteria Uji:

$$
F_{\text {tabel }}=F_{\alpha, v_{1}, v_{2}}=F_{0,05 ; 8 ; 7}=3,73
$$

Didapat nilai $M<F_{\text {tabel }}=1,12332<3,73$ yang artinya $H_{0}$ diterima. Maka dapat disimpulkan data kerusakan terdistribusi Weibull.

\subsection{Penentuan Nilai Parameter}

Penentuan nilai parameter dari distribusi yang terpilih digunakan untuk mengetahui parameter dari data TTF yang telah diuji index of fit dan goodness of fit. Berikut adalah perhitungan dalam penentuan nilai parameter untuk masing-masing bearing :

\section{a. Metode Least Square}

Penaksir parameter distribusi Weibull adalah sebagai berikut :

$$
\begin{aligned}
& a=\frac{1}{n}\left(\sum_{i-1}^{n} Y_{i}-b \sum_{i-1}^{n} X_{i}\right)=\bar{Y}-b \bar{X} \\
& b=\frac{\sum_{i=1}^{n} X_{i} Y_{i}-Y \sum_{i=1}^{n} X_{i}}{\left(\sum_{i=1}^{n} X_{i}{ }^{2}-R \sum_{i=1}^{n} X_{i}\right)}
\end{aligned}
$$

dengan,

$$
\begin{gathered}
x_{i}=\ln t_{i} \\
y_{i}=\ln \ln \left[\frac{1}{1-F\left(t_{i}\right)}\right]
\end{gathered}
$$

$$
F\left(t_{i}\right)=\frac{i-0,3}{n+0,4}
$$

dimana :

$$
\begin{aligned}
& t_{i}: \text { data kerusakan ke }-\mathrm{i} \\
& i \quad: 1,2,3, \ldots, \mathrm{n}
\end{aligned}
$$

Dengan kedua konstanta $a$ dan $b$ maka parameter distribusi Weibull dapat ditentukan parameter yaitu:

$$
\beta=b
$$




$$
\begin{aligned}
& \theta= \\
& e^{\frac{-a}{b}}
\end{aligned}
$$

Dari perhitungan nilai parameter $\theta$ dan $\beta$ menggunakan perhitungan diatas, didapatkan hasil sebagai berikut

Tabel 2 Hasil parameter distribusi Weibull

\begin{tabular}{|l|c|c|}
\hline \multirow{2}{*}{ Komponen } & \multicolumn{2}{|c|}{ Nilai Parameter } \\
\cline { 2 - 3 } & $\theta$ & $\beta$ \\
\hline Bearing 6001 & 9773,64352 & 26,30218 \\
ZZ & & \\
\hline Bearing 6205 & 9794,68238 & 26,24173 \\
\hline $\begin{array}{l}\text { Bearing 0606 } \\
\text { ZZ }\end{array}$ & 9752,47337 & 26,22811 \\
\hline $\begin{array}{l}\text { Thrust } \\
\text { Bearing }\end{array}$ & 9731,14054 & 26,29154 \\
\hline
\end{tabular}

\section{b. Metode Estimasi Maksimum Likelihood}

Penaksir parameter distribusi Weibull adalah sebagai berikut :

Pembentukan fungsi likelihood :

$$
\begin{gathered}
f(t ; \beta ; \theta)=\frac{\beta}{\theta}\left(\frac{t}{\theta}\right)^{\beta-1} e^{-\left(\frac{t}{\theta}\right)^{\beta}} \\
(9) \\
L(t ; \beta ; \theta)=f\left(t_{1} ; \beta ; \theta\right) f\left(t_{2} ; \beta ; \theta\right) \ldots f\left(t_{n} ; \beta ; \theta\right) \\
=\frac{\beta}{\theta}\left(\frac{t_{1}}{\theta}\right)^{\beta-1} e^{-\left(\frac{t_{1}}{\theta}\right)^{\beta}} \cdot \frac{\beta}{\theta}\left(\frac{t_{2}}{\theta}\right)^{\beta-1} e^{-\left(\frac{t_{n}}{\theta}\right)^{\beta}} \ldots \cdot \frac{\beta}{\theta}\left(\frac{t_{n}}{\theta}\right)^{\beta-1} e^{-\left(\frac{t_{n}}{\theta}\right)^{\beta}}
\end{gathered}
$$

Pembentukan Log Likelihood :

$$
\ln L(t ; \beta ; \theta)=l(\beta ; \theta ; t)
$$




$$
\begin{gathered}
\quad l(\beta ; \theta ; t)=n \ln \beta-n \beta \ln \theta+\ln \prod_{i=1}^{n} t_{i}{ }^{\beta-1}-\frac{1}{\theta^{\beta}} \sum_{i=1}^{n}\left(t_{i}\right)^{\beta} \\
=n \ln \beta-n \beta \ln \theta+(\beta-1) \ln \prod_{i=1}^{n} t_{i}-\frac{1}{\theta^{\beta}} \sum_{i=1}^{n}\left(t_{i}\right)^{\beta} \\
=n \ln \beta-n \beta \ln \theta+(\beta-1) \ln \left(t_{1}, t_{2} \cdots t_{n}\right)-\frac{1}{\theta^{\beta}} \sum_{i=1}^{n}\left(t_{i}\right)^{\beta} \\
=n \ln \beta-n \beta \ln \theta+(\beta-1) \sum_{i=1}^{n} \ln t_{i}-\frac{1}{\theta^{\beta}} \sum_{i=1}^{n}\left(t_{i}\right)^{\beta}
\end{gathered}
$$

Karena

$$
\begin{gathered}
\frac{\partial l(\beta ; \theta ; t)}{\partial \theta}=0, \text { maka } \\
=\frac{\partial}{\partial \theta}\left[n \ln \beta-n \beta \ln \theta+(\beta-1) \sum_{i=1}^{n} \ln t_{i}-\frac{1}{\theta^{\beta}} \sum_{i=1}^{n}\left(t_{i}\right)^{\beta}\right] \\
=-\frac{n \beta}{\theta}+\frac{\beta}{\theta^{(\beta+1)}} \sum_{i=1}^{n}\left(t_{i}\right)^{\beta}=0 \\
-\frac{n \beta}{\theta}=-\frac{\beta}{\theta^{(\beta+1)}} \sum_{i=1}^{n}\left(t_{i}\right)^{\beta} \\
\frac{n \beta}{\theta}=\frac{\beta}{\theta^{(\beta+1)}} \sum_{i=1}^{n}\left(t_{i}\right)^{\beta} \\
\theta=\frac{\beta}{\theta^{(\beta+1)}} \sum_{i=1}^{n}\left(t_{i}\right)^{\beta} \cdot \theta \\
n \beta=\frac{\beta}{\theta^{\beta}} \sum_{i=1}^{n}\left(t_{i}\right)^{\beta} \\
\theta^{\beta}=\frac{\sum_{i=1}^{n}\left(t_{i}\right)^{\beta}}{n} \\
\theta=\frac{\sum_{i=1}^{n}\left(t_{i}\right)^{\beta}}{\theta^{\beta}}
\end{gathered}
$$

Karena

$$
\frac{\partial l(\beta ; \theta ; t)}{\partial \beta}=0, \text { maka }
$$




$$
\begin{aligned}
= & \frac{\partial}{\partial \beta}\left[\ln \beta-n \beta \ln \theta+(\beta-1) \sum_{i=1}^{n} \ln t_{i}-\frac{1}{\theta^{\beta}} \sum_{i=1}^{n}\left(t_{i}\right)^{\beta}\right] \\
= & \frac{\partial}{\partial \beta}\left[\ln \beta-n \beta \ln \theta+(\beta-1) \sum_{i=1}^{n} \ln t_{i}-\sum_{i=1}^{n}\left(\frac{t_{i}}{\theta}\right)^{\beta}\right] \\
= & \frac{n}{\beta}-n \ln \theta+\sum_{i=1}^{n} \ln t_{i}-\sum_{i=1}^{n}\left(\frac{t_{i}}{\theta}\right)^{\beta} \ln \left(\frac{t_{i}}{\theta}\right)=0 \\
& -\sum_{i=1}^{n}\left(\frac{t_{i}}{\theta}\right)^{\beta} \ln \left(\frac{t_{i}}{\theta}\right)-n \ln \theta+\frac{n}{\beta}=-\sum_{i=1}^{n} \ln t_{i} \\
& \sum_{i=1}^{n}\left(\frac{t_{i}}{\theta}\right)^{\beta} \ln \left(\frac{t_{i}}{\theta}\right)+n \ln \theta-\frac{n}{\beta}=\sum_{i=1}^{n} \ln t_{i} \\
& \sum_{i=1}^{n}\left(\frac{t_{i}}{\theta}\right)^{\beta} \ln \left(t_{i}\right)-\sum_{i=1}^{n}\left(\frac{t_{i}}{\theta}\right)^{\beta} \ln \theta+n \ln \theta-\frac{n}{\beta}=\sum_{i=1}^{n} \ln t_{i}
\end{aligned}
$$

Subtitusi :

$$
\begin{array}{r}
\frac{1}{\theta^{\beta}} \sum_{i=1}^{n} t_{i}{ }^{\beta} \ln t_{i}-n \ln \theta+n \ln \theta-\frac{n}{\beta}=\sum_{i=1}^{n} \ln t_{i} \\
\frac{\sum_{i=1}^{n} t_{i}{ }^{\beta} \ln t_{i}}{\frac{\sum_{i=1}^{n} t_{i}{ }^{\beta}}{n}}-\frac{n}{\beta}=\sum_{i=1}^{n} \ln t_{i} \\
\frac{\sum_{i=1}^{n} t_{i}{ }^{\beta} \ln t_{i}}{\sum_{i=1}^{n} t_{i}{ }^{\beta}}-\frac{1}{\beta}=\frac{\sum_{i=1}^{n} \ln t_{i}}{n}
\end{array}
$$

Nilai dugaan parameter bagi $\beta$ diperoleh melalui pendekatan iterasi metode Newton-Raphson dengan mengganggap bahwa:

$$
f(\beta)=\frac{\partial l(\beta ; \theta ; t)}{\partial \beta}=0
$$

Langkah-langkah metode Newton-Raphson untuk mencari dugaan parameter adalah sebagai berikut :

1. Menentukan nilai awal $\beta_{0}$ 
2. Menentukan persamaan $f(\beta)$

$$
f(\beta)=\frac{\sum_{i=1}^{n} t_{i}{ }^{\beta} \ln t_{i}}{\sum_{i=1}^{n} t_{i}{ }^{\beta}}-\frac{1}{\beta}-\frac{\sum_{i=1}^{n} \ln t_{i}}{n}
$$

dan turunan pertama dari $f(\beta)$ adalah

$$
\begin{aligned}
& f^{\prime}(\beta)=\frac{d f(\beta)}{d \beta} \\
& \frac{\sum_{i=1}^{n} t_{i}{ }^{\beta} \sum_{i=1}^{n} t_{i}{ }^{\beta}\left(\ln t_{i}\right)^{2}-\left(\sum_{i=1}^{n} t_{i}{ }^{\beta} \ln t_{i}\right)^{2}}{\left(\sum_{i=1}^{n} t_{i}{ }^{\beta}\right)^{2}}+\frac{1}{\beta^{2}}
\end{aligned}
$$

3. Subtitusi persamaan $f(\beta)$ dan turunan pertamanya $f^{\prime}(\beta)$ kedalam rumus metode Newton-Raphson

$$
\begin{aligned}
& \beta_{n+1}=\beta_{n}-\frac{f\left(\beta_{n}\right)}{f^{\prime}\left(\beta_{n}\right)} \\
& \beta_{n+1}=\beta_{n}-\frac{\frac{\sum_{i=1}^{n} t_{i}{ }^{\beta} \ln t_{i}}{\sum_{i=1}^{n} t_{i}{ }^{\beta}}-\frac{1}{\beta}-\frac{\sum_{i=1}^{n} \ln t_{i}}{n}}{\frac{\sum_{i=1}^{n} t_{i}{ }^{\beta} \sum_{i=1}^{n} t_{i}{ }^{\beta}\left(\ln t_{i}\right)^{2}-\left(\sum_{i=1}^{n} t_{i}{ }^{\beta} \ln t_{i}\right)^{2}}{\left(\sum_{i=1}^{n} t_{i}{ }^{\beta}\right)^{2}}+\frac{1}{\beta^{2}}}
\end{aligned}
$$

4. Iterasi dihentikan jika nilainya telah konvergen. Artinya, nilai $\beta_{n+1}$ itulah yang dijadikan nilai aproksimasi untuk $\beta$.

Dari perhitungan nilai parameter $\theta$ dan $\beta$ menggunakan perhitungan diatas, didapatkan hasil sebagai berikut :

Tabel 3 Hasil parameter metode Newton-Raphson

\begin{tabular}{|ll|l|l|}
\hline \multicolumn{2}{|c|}{ Komponen } & \multicolumn{2}{c|}{ Nilai Parameter } \\
\cline { 3 - 4 } & $\theta$ & $\beta$ \\
\hline $\begin{array}{l}\text { Bearing } \\
\text { ZZ }\end{array}$ & 9001 & 31,75040 \\
\hline $\begin{array}{l}\text { Bearing } \\
\text { ZZ }\end{array}$ & 9705 & \\
\hline $\begin{array}{l}\text { Bearing } \\
\text { ZZ }\end{array}$ & 9606 & 9739,5509625 & 31,67550 \\
\hline Thrust Bearing & 9718,58937 & 31,59320 \\
\hline
\end{tabular}


3.4 Perhitungan Nilai Keandalan, Laju Kerusakan, Umur, Sisa Umur dan Nilai Error Masing-masing Komponen

Setelah didapatkan nilai parameter selanjutnya adalah dilakukan penghitungan nilai keandalan, laju kerusakan, umur dan sisa umur dari masing-masing bearing.

\section{a.Metode Least Square}

Tabel 4 Hasil parameter metode Least Square

\begin{tabular}{|l|l|l|}
\hline \multicolumn{1}{|c|}{ Komponen } & \multicolumn{1}{|c|}{ Keandalan } & \multicolumn{1}{c|}{ Laju Kerusakan } \\
\hline $\begin{array}{l}\text { Bearing 6001 } \\
\text { ZZ }\end{array}$ & 0,94541 & 0,00017 \\
\hline $\begin{array}{l}\text { Bearing 6205 } \\
\text { ZZ }\end{array}$ & 0,94799 & 0,00016 \\
\hline $\begin{array}{l}\text { Bearing 0606 } \\
\text { ZZ }\end{array}$ & 0,94185 & 0,00018 \\
\hline Thrust Bearing & 0,93892 & 0,00019 \\
\hline
\end{tabular}

Tabel 5 Hasil parameter metoda Least Square

\begin{tabular}{|l|l|l|}
\hline \multicolumn{1}{|c|}{ Komponen } & \multicolumn{1}{|c|}{ Umur } & \multicolumn{1}{c|}{$\begin{array}{c}\text { Sisa } \\
\text { Umur }\end{array}$} \\
\hline $\begin{array}{l}\text { Bearing 6001 } \\
\text { ZZ }\end{array}$ & $\begin{array}{l}1 \text { tahun 1 bulan 29 } \\
\text { hari }\end{array}$ & $\begin{array}{l}11 \text { hari 18 } \\
\text { jam }\end{array}$ \\
\hline Bearing 6205 & 1 tahun 1 bulan 3 & 16 hari 21 \\
ZZ & hari & jam \\
\hline $\begin{array}{l}\text { Bearing 0606 } \\
\text { ZZ }\end{array}$ & $\begin{array}{l}\text { hahun 1 bulan 2 } \\
\text { hari hari 15 jam }\end{array}$ \\
\hline Thrust Bearing & $\begin{array}{l}1 \text { tahun 1 bulan 1 } \\
\text { hari }\end{array}$ & 7 hari 13 jam \\
\hline
\end{tabular}




\section{b.Metode Estimasi Maksmimum Likelihood}

Tabel 6 Hasil parameter Metode Estimasi Maksmimum Likelihood

\begin{tabular}{|l|l|l|}
\hline \multicolumn{1}{|c|}{ Komponen } & \multicolumn{1}{|c|}{ Keandalan } & Laju Kerusakan \\
\hline $\begin{array}{l}\text { Bearing 6001 } \\
\text { ZZ }\end{array}$ & 0,96827 & 0,00012 \\
\hline $\begin{array}{l}\text { Bearing 6205 } \\
\text { ZZ }\end{array}$ & 0,97011 & 0,00011 \\
\hline $\begin{array}{l}\text { Bearing 0606 } \\
\text { ZZ }\end{array}$ & 0,96578 & 0,00013 \\
\hline Thrust Bearing & 0,96309 & 0,00014 \\
\hline
\end{tabular}

\begin{tabular}{|l|l|l|}
\hline \multicolumn{1}{|c|}{ Komponen } & \multicolumn{1}{|c|}{ Umur } & \multicolumn{1}{c|}{$\begin{array}{l}\text { Sisa } \\
\text { Umur }\end{array}$} \\
\hline $\begin{array}{l}\text { Bearing 6001 } \\
\text { ZZ }\end{array}$ & $\begin{array}{l}1 \text { tahun 1 bulan 4 } \\
\text { hari }\end{array}$ & $\begin{array}{l}\text { 23 hari 10 } \\
\text { jam }\end{array}$ \\
\hline $\begin{array}{l}\text { Bearing 6205 } \\
\text { ZZ }\end{array}$ & $\begin{array}{l}1 \text { tahun 1 bulan 5 } \\
\text { hari }\end{array}$ & 25 hari 1 jam \\
\hline $\begin{array}{l}\text { Bearing 0606 } \\
\text { ZZ }\end{array}$ & $\begin{array}{l}\text { hahun 1 bulan 11 } \\
\text { hari }\end{array}$ & 29 hari 1 jam \\
\hline Thrust Bearing & $\begin{array}{l}1 \text { tahun 1 bulan 2 } \\
\text { hari }\end{array}$ & \begin{tabular}{l} 
jam hari 14 \\
\hline
\end{tabular} \\
\hline
\end{tabular}

Setelah didapatkan nilai keandalan, laju kerusakan, umur dan sisa umur pada masing-masing bearing, maka langkah selanjutnya adalah membandingkan nilai error pada masing-masing metode untuk mengetahui metode terbaik dalam menaksir parameter data TTF dari masing-masing bearing pada Mesin Sakurai Oliver-66. Persamaan didefinisikan sebagai [8]:

$$
M S E=\sum_{i=1}^{n}\left|\widehat{F\left(t_{\imath}\right)}-F\left(t_{i}\right)\right|^{2}
$$

Perhitungan nilai error pada masing-masing komponen :

Tabel 7 Hasil perhitungan error

\begin{tabular}{|c|c|c|}
\hline Komponen & Metode LS & Metode MLE \\
\hline Bearing 6001 ZZ & 0,06397 & 0,12583 \\
\hline
\end{tabular}




\begin{tabular}{|l|l|l|}
\hline Bearing 6205 ZZ & 0,06191 & 0,12551 \\
\hline Bearing 0606 ZZ & 0,06470 & 0,12647 \\
\hline Thrust Bearing & 0,05421 & 0,11445 \\
\hline
\end{tabular}

\section{Kesimpulan}

Berdasarkan analisis dan pembahasan pada bab sebelumnya, diperoleh kesimpulan sebagai berikut:

Untuk Metode Least Square :

Nilai keandalan dari bearing 6001 ZZ 0,94541; bearing 6205

1. Nilai keandalan dari bearing 6001 ZZ 0,94541; bearing 6205 ZZ

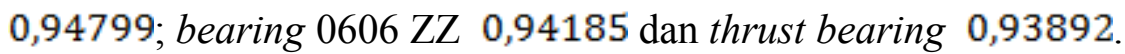

2. Nilai laju kerusakan dari bearing 6001 ZZ 0,00017; bearing 6205 ZZ 0,00016; bearing 0606 ZZ 0,00018 dan thrust bearing 0,00019.

3. Nilai taksiran umur dari bearing $6001 \mathrm{ZZ} 1$ tahun 1 bulan 29 hari; bearing $6205 \mathrm{ZZ} 1$ tahun 1 bulan 3 hari; bearing $0606 \mathrm{ZZ} 1$ tahun 1 bulan 2 hari dan thrust bearing 1 tahun 1 bulan 1 hari.

4. Nilai taksiran sisa umur dari bearing $6001 \mathrm{ZZ} 11$ hari 18 jam; bearing 6205 ZZ 16 hari 21 jam; bearing 0606 ZZ 9 hari 15 jam dan thrust bearing 7 hari 13 jam.

Untuk Metode Estimasi Maksimum Likelihood:

1. Nilai keandalan dari bearing 6001 ZZ 0,96827; bearing 6205 ZZ

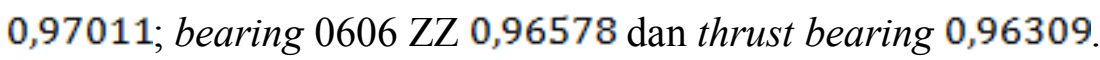

2. Nilai laju kerusakan dari bearing 6001 ZZ 0,00012; bearing 6205 ZZ sebesar 0,00011; bearing 0606 ZZ 0,00013 dan thrust bearing 0,00014.

3. Nilai taksiran umur dari bearing 6001 ZZ 1 tahun 1 bulan 4 hari; bearing $6205 \mathrm{ZZ} 1$ tahun 1 bulan 5 hari; bearing 0606 ZZ 1 tahun 1 bulan 11 hari dan thrust bearing 1 tahun 1 bulan 2 hari.

4. Nilai taksiran sisa umaur dari bearing 6001 ZZ 23 hari 10 jam; bearing 6205 ZZ 25 hari 1 jam; bearing 0606 ZZ 29 hari 1 jam dan thrust bearing 19 hari 14 jam. 
Dalam membandingkan metode terbaik dalam menduga parameter distribusi Weibull dengan dua parameter digunakan perbandingan Rata-Rata Kuadrat Galat (Mean Square Error). Metode yang terbaik adalah metode yang memiliki nilai MSE minimum. Metode terbaik dalam pendugaan menggunakan data TTF bearing 6001 ZZ, bearing 6205 ZZ, bearing 0606 ZZ , thrust bearing Mesin Sakurai Oliver-66 Metode Least Square.

\section{Pustaka}

[1] Suhardjono (2005). “Analisis Sinyal Getaran Pada Tingkat Kerusakan Bantalan", Puslit Mechanical Journal. Jurusan Teknik Industri, FTI, Institut Teknologi Sepuluh Nopember, Surabaya.

[2]Lee. (2016). “Analysis Life Time For Rolling Element Bearing".University of Rochester, New York. Vol 2, No.4, 42-45.

[3]Pratiwi,dkk. (2015). "Penggunaan Analisa Ketahanan Hidup Untuk Penentuan Periode Garansi dan Harga Produk Pada Data Waktu Hidup Lampu Neon". Jurusan Statistika, Universitas Diponegoro, Semarang. Vol 4, No.3, 463-476.

[4]Dhillon, B. S.(1997). "Reliability Engineering in System Design and Operation”. Van Nostrand Reinhold Company, Inc., Singapore.

[5]Sudarno. (2009). “Karakteristik Umur Produk Pada Model Weibull”. Jurusan Statistika,Universitas Diponegoro, Semarang. Vol.2, No.2, 105110.

[6]Hall and Wellner. (1981). “Mean Residual Life”. University of Rochester, New York.

[7]Ebeling, Charles E. (2003). “An Introduction to Reliability and Maintainability Engineering".United Kingdom:The British Library Document Supply Centre.

[8] Lei, Y. (2008). “Evaluation Of Three Methods For Estimating The Weibull Distribution Parameters Of Chinese Pine”. Chinese Academy 
of Forestry, Beijing (China). Research Inst. of Resource Information and Techniques. 